\title{
Sistemas de moeda local: uma investigação sobre seus potenciais a partir do caso do Banco Bem em Vitória/ES ${ }^{1}$

\author{
Melissa Silva Menezes ${ }^{2}$
} \\ Marco Aurélio Crocco ${ }^{3}$
}

\begin{abstract}
Resumo
A finalidade deste trabalho é atentar para um tema ainda muito pouco investigado: os Sistemas de Moeda Local (SML), que são, grosso modo, um acordo feito entre pessoas de uma comunidade para o uso de um meio de pagamento com validade restrita ao espaço onde vivem. Para o alcance desse objetivo, procurou-se realizar um levantamento da literatura nacional e internacional existente acerca do tema, fez-se um exercício de teorização com base na teoria pós-keynesiana e efetuou-se o estudo exploratório de um caso brasileiro, o Banco Bem - situado na cidade de Vitória/ES. O intuito não é inferir resultados concludentes - o que seria precipitado dado o seu caráter recente - mas aumentar sua compreensão e apontar suas potencialidades e limites.
\end{abstract}

Palavras-chave: Moeda local; Exclusão financeira; Desenvolvimento local; Economia póskeynesiana.

\begin{abstract}
Local money systems: an investigation towards its potentialities based on the study of the Banco Bem in Vitória, Brazil

The aim of this paper is to investigate towards a relatively unexplored area: the Local Money Systems (LMS), that are, in short, an agreement amongst the population of a community to use a mean of payment which is valid only in that particular space where they live. To achieve such objectives, it was made a survey of the existent national and international bibliography on this topic, an exercise of theorization based on the post-keynesian theory and an exploratory study of a Brazilian case, the Banco Bem located in the city of Vitória/ES. The goal was not to infer concluding results - which would be precipitate because of its early character - but to expand its understanding and to indicate its potentialities and limits.
\end{abstract}

Key words: Local money; Financial exclusion; Local development; Post-Keynesian economics. JEL R51, G21.

\section{Introdução}

A importância da moeda para o desenvolvimento econômico ainda é questão largamente desconsiderada por grande parte das teorias em economia, e

(1) Trabalho recebido em abril de 2007 e aprovado em março de 2008.

(2) Mestre em Economia pelo Centro de Desenvolvimento e Planejamento Regional de Minas Gerais (Cedeplar)/Universidade Federal de Minas Gerais (UFMG), Belo Horizonte, MG, Brasil. E-mail: melnezes@gmail.com.

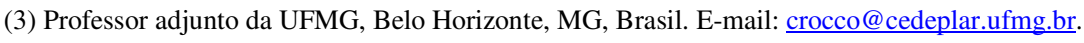


por essa razão se abre um amplo leque de perspectivas para pesquisas. A recorrência desse tipo de carência se deve, conforme sublinham Sicsú e Crocco (2003), à influência exercida pelas correntes ortodoxas na agenda de pesquisa de economia regional. Como se sabe, essas correntes consideram a moeda como neutra no longo prazo, não tendo assim nenhuma influência sobre o lado real da economia. Assim, não existiria a necessidade de estudar os impactos da moeda na dinâmica regional, uma vez que essa influência seria, por definição, nula tanto em nível nacional quanto regional.

Em relação a estudos regionais, segundo Martin (1999), foi somente a partir da década de 1980 que houve o surgimento de uma "geografia da moeda". No Brasil, a pesquisa é incipiente e encontra espaço crescente entre os economistas afeitos ao pós-keynesianismo, vertente que enfatiza a interferência da moeda na produção. Ressalte-se que, se pouca atenção tem sido dada ao papel da moeda na economia regional, quando se abordam questões como desenvolvimento local e de comunidades, ou seja, no que podemos incluir no âmbito intrarregional, essa deficiência é ainda mais acentuada. Este trabalho se insere nesse contexto e pretende-se que ele cubra, ainda que parcialmente, tais lacunas.

Baseia-se aqui na concepção da Economia Monetária, assentada em Keynes, em que a moeda importa por influenciar, tanto no curto como no longo prazo, o comportamento e as decisões dos agentes econômicos. Isso ocorre porque a taxa de juros toma um significado diferente daquele que é atribuído pelas escolas clássicas: ela não é a taxa que equilibra a poupança e o investimento, e sim a que baliza a interação entre a oferta de moeda e a demanda pela mesma. Essa interação é pautada pela preferência pela liquidez, isto é, a preferência por deter o ativo mais líquido e seguro, a moeda, em vez de investir nos demais ativos. Tal preferência, por sua vez, está diretamente relacionada à incerteza quanto ao desempenho futuro da economia. Quanto maior ela for, maiores serão as taxas de juros, como recompensa aos agentes que abram mão de deter a moeda em prol de outros ativos menos líquidos (Carvalho, 2006).

Por esse ponto de vista, é fácil perceber que o sistema financeiro é capaz de interferir enormemente na economia por intermédio de um processo duplo: pode tanto reduzir o grau de incerteza dos agentes, protegendo-os de oscilações e consequentemente incentivando a produção de riqueza real, quanto aumentar a incerteza, e consequentemente a preferência pela liquidez dos agentes, quando é ineficaz ou pouco abrangente. A moeda, portanto, interfere no desenvolvimento econômico e por isso merece ser estudada.

Com esse pano de fundo, surge a indagação sobre a forma como a vinculação da moeda ao espaço pode afetar a dinâmica da economia. Ao se observar o comportamento de variáveis financeiras no espaço, a não neutralidade 
da moeda fica ainda mais evidenciada. Estudos recentes apontam para os efeitos deletérios a que incorrem regiões afetadas pela chamada exclusão financeira, que consiste na carência ou inexistência de serviços que facilitam e ampliam o uso da moeda, ou seja, os serviços bancários e financeiros (Leyshon; Thrift, 1996, 1997).

A criação de uma moeda que se restringe a circular num determinado limite territorial - principal objeto deste trabalho - desponta como mais uma evidência de que a moeda não é simplesmente um "véu que encobre as trocas" numa sociedade capitalista, posto que a principal finalidade de um mecanismo como este é conservar e ampliar a riqueza real no local. Ao contrário da moeda nacional, que tem relação de troca com moedas de outros países, a moeda local não tem validade alguma fora daquele espaço, o que significa que o seu uso tem que se dar ali, invariavelmente. Assim, em vez de realizar consumo e investimento em outros lugares, os detentores da moeda local a empregam na economia local, o que a favorece.

O surgimento de moedas locais, surpreendentemente e na contramão das tendências da globalização, tem proliferado mundo afora numa infinidade de formas. A motivação deste estudo advém, portanto, do caráter recente de sua existência - os primeiros casos surgem nos anos 1980 e se multiplicam a partir de meados dos anos 1990 - e consequente carência de trabalhos acadêmicos realizados, notadamente nas ciências econômicas. No Brasil, essa ausência é ainda maior.

Sem deixar de atentar para os inúmeros aspectos sociológicos dessas experiências, o enfoque primordial é dado às características econômicas e espaciais dos mesmos. Mais especificamente, a intenção é enfatizar a possível relação entre exclusão financeira e o surgimento de iniciativas locais de criação de moedas próprias como alternativa para o desenvolvimento. O objetivo precípuo é proporcionar um entendimento maior sobre esse assunto, na expectativa de que se abram caminhos para a pesquisa e o tratamento do tema de forma idônea. Para tanto, foi feito um estudo de caso de uma moeda local no Brasil - a do Banco Bem, localizado em Vitória/Espírito Santo. Deve ficar bem claro que aqui o intuito é meramente exploratório; não se pretende inferir resultados concludentes nem relações determinísticas, o que seria bastante precipitado dada a incipiência do tema.

No tópico subsequente, está exposta uma breve revisão da literatura relacionada à exclusão financeira e o tópico 2 destaca a importância do local em tempos globais. O terceiro tópico aborda diretamente o bojo do trabalho, citando as práticas existentes de moedas locais e recorrendo aos fundamentos da teoria pós-keynesiana. Por fim, a seção 4 reporta-se ao estudo de caso e na última alguns 
tópicos considerados proeminentes são debatidos, encerrando as principais conclusões desenvolvidas.

\section{Exclusão financeira}

A hipótese aventada aqui, e que permeia todo o trabalho, é a de que existe relação entre desenvolvimento econômico e desenvolvimento financeiro, motivo pelo qual a exclusão financeira aparece como uma amarra às potencialidades locais. Procura-se, assim, investigar se a criação de uma moeda própria pode ser vista como alternativa a essa exclusão.

A literatura em que se baseia a presente revisão sobre exclusão financeira está inserida na linha chamada de geografia econômica e parte de suposições marxistas acerca da lógica de competição do capital e busca de lucros. Como aponta Leyshon (2003), o pioneiro em tratar da exclusão financeira nesses termos foi David Harvey, na década de 1970. Para Harvey (1985), o capital é organizado espacialmente como uma pré-condição à sua perpetuação. A concentração econômica é um dos resultados inexoráveis.

A exclusão financeira pode ser definida como sendo a precariedade ou mesmo a ausência de acesso a serviços financeiros em geral, por uma parcela específica da população. Ela decorre, como elucidam Leyshon e Thrift (1996, 1997), do cálculo de risco feito pelos bancos em suas decisões de operações. Como as instituições financeiras assumem que o risco de prejuízo ou inadimplência é inversamente proporcional à renda e à riqueza de seus clientes, ocorre que, espacialmente, a oferta de serviços é menor em locais economicamente mais atrasados e para indivíduos desprovidos. Ademais, a facilidade dos bancos em adquirir informações é outro determinante importante da alocação dos recursos financeiros, sendo evidente que os custos de se obter informações sobre clientes de renda e/ou riqueza reduzidas ou de pequenos empreendimentos são maiores (Kumar, 2004). Em termos regionais, a oferta de serviços bancários será maior quanto mais elevada for a confiança que os bancos depositam no desempenho futuro da economia da região e nos tomadores de empréstimo. Como afirma Dow (1999), essa confiança está diretamente relacionada à quantidade de conhecimento adquirido pelos bancos.

Além dos custos de informação, os de transação são também relevantes na delineação da exclusão. Como as transações advindas de clientes de baixa renda são menores em volume e mesmo em qualidade, do ponto de vista do ofertante de serviço, ${ }^{4}$ o custo relativo é maior. Isso leva à cobrança de maiores taxas de juros e de serviços aos clientes menores, para que os maiores custos operacionais sejam

(4) Grosso modo, clientes de pouca renda não realizam investimentos, limitando-se à manutenção de seu dinheiro em conta corrente ou poupança. 
compensados. Não obstante, cada vez mais, por razões de eficiência e segurança, a moeda-papel cede espaço a operações eletrônicas, o que dificulta a realização de transações sem acesso a algum tipo de instituição financeira e aumenta a discriminação contra aqueles que não têm condições de custear o uso de tecnologias como a internet.

Vale acrescentar que o acesso a serviços bancários é dificultado ainda por impedimentos que vão das exigências burocráticas e de garantias até as variadas taxas, como, por exemplo, o cheque especial e as taxas de administração de contas, cartões e talões de cheques. O aumento de serviços especializados para clientes de alta renda, inclusive com agências exclusivas, se concebe também como uma forma de exclusão da população pobre e de "superinclusão" de uma minoria rica. Advertem Leyshon e Thrift:

O corolário destes processos de inclusão são processos de exclusão financeira, que desproporcionadamente afetam os pobres e os segmentos mais desamparados da sociedade. Através de meios diretos e indiretos estes grupos estão sendo apagados das bases de clientes das instituições financeiras convencionais (1996, p. 1151, tradução nossa).

Conforme esses mesmos autores (Leyshon; Thrift, 1997), a existência de infraestrutura financeira é fundamental para o desenvolvimento regional, pois possibilita aos produtores incrementar sua produtividade através da realização de investimentos e atribui bem-estar aos indivíduos, que podem tomar decisões de consumo e poupança não só no curto como no longo prazo, além de serem mais capazes de se proteger de flutuações econômicas como recessões e inflação. Sem esse acesso, a conduta da vida cotidiana numa sociedade capitalista contemporânea é bastante problemática. Assim sendo, a exclusão financeira gera um processo circular vicioso, já que a falta de acesso aos serviços bancários entrava o desenvolvimento, o que por sua vez leva a uma posição ainda mais reticente por parte do sistema financeiro. $O$ resultado é a exclusão não apenas financeira, mas também social e econômica.

Leyshon e Thrift (1996) apresentam um histórico do "abandono financeiro" ocorrido nos Estados Unidos e na Inglaterra desde os anos 1970 e intensificado a partir do início da década de 1990. Para eles, surgiram "espaços vazios" na geografia da provisão de serviços financeiros em países desenvolvidos, o que tem importantes implicações do ponto de vista do aprofundamento do desenvolvimento desigual, já que esses espaços estão sempre associados a problemas econômicos e sociais e essa falta de acesso só faz agravar tais problemas.

Se o processo de exclusão em países desenvolvidos culminou na década de 1990, nos países subdesenvolvidos ele já se fazia notar ainda nos anos 1980. Entre 1980 e 1985, os maiores bancos mundiais fecharam 24\% dos seus escritórios 
localizados em países subdesenvolvidos. (Leyshon; Thrift, 1997, p. 225). No Brasil, a década de 1980 foi de forte crise econômica, marcando o início da crise dos bancos estaduais e a consequente onda de concentração no setor. Os anos 1990 assistiram a um vasto programa de reestruturação dos bancos, resultando em forte redução nas despesas com pessoal, aumento de tarifas e diminuição do número de agências bancárias nas regiões mais pobres (Sicsú; Crocco, 2003). A exclusão financeira no país é latente, tanto com relação aos consumidores, quanto com as empresas, e se expressa ainda de maneira pertinaz regionalmente. Carvalho e Abramovay (2004, p. 20) alertam: "O sistema financeiro brasileiro sustenta há muito tempo um desempenho paradoxal: não atende à demanda por crédito e financiamento da maioria dos setores produtivos e, ao mesmo tempo, preserva margens de lucro excepcionais (...)".

Faz-se profícua, pois, a reflexão sobre formas possíveis de se combater a exclusão financeira. Leyshon e Thrift (1997), em consonância com a linha de pensamento adotada aqui, vão além de sugestões paliativas e advogam que a exclusão financeira pode e precisa ser evitada pelo aparato estatal, através de leis reguladoras, e/ou por meio da implementação de uma infraestrutura financeira alternativa. Quanto à primeira saída, a regulação, de acordo com os autores, deve se dar de forma a diminuir o poder do setor financeiro, e não pode ser baseada unicamente na eficiência econômica, pois isso só favoreceria o aumento da concentração de renda e riqueza.

Já com relação à segunda possibilidade, os autores apontam para o crescimento de "instituições alternativas de acumulação", resistentes à exclusão. Elas são de tipos variados e poderiam ser classificadas em quatro categorias: 1) bancos de desenvolvimento comunitários, cuja prioridade seria a recuperação da infraestrutura urbana e realização de empréstimos para negócios locais; 2) uniões de crédito, que oferecem pequenos empréstimos individuais e substituem a atuação de bancos de varejo; 3) associações de crédito e poupança, que são agrupamentos informais que captam poupança e se emprestam ao longo do tempo; e 4) sistemas de troca e comércio locais através de uma moeda paralela à nacional, os Lets (Local Exchange and Trading Systems). Sobre estes, nos deteremos com mais afinco adiante, na seção 3. Antes, faremos uma breve revisão sobre a literatura que trata de desenvolvimento local.

\section{A importância do local}

Neste ponto em que se detecta a existência de instituições alternativas locais, abre-se espaço para a discussão do papel do local em tempos globais, quando a exclusão financeira toma proporções cada vez mais amplas, como se viu na seção anterior. A partir dos anos 1970, tornou-se evidente a impossibilidade dos setores privado e público em responder ao crescimento do desemprego e da 
desigualdade (Williams et al., 2001). Enquanto se presencia no setor privado uma crescente desvinculação entre produtividade e emprego, através de inovações tecnológicas que continuamente permitem a dispensa de mão de obra ao mesmo tempo em que se amplia a produção, o Estado sofre pressões para a minimização de sua intervenção (Amim et al., 2006).

O chamado terceiro setor cresce em importância e uma alternativa cada vez mais considerada é a implementação de circuitos locais de transações com moedas paralelas às convencionais. Segundo Amin et al. (2006), apesar do grande crescimento desse tipo de experiências de desenvolvimento local e de várias tentativas de estudar esses fenômenos, ainda são incipientes os estudos acadêmicos a respeito. Como se verá com mais desvelo adiante, esses circuitos de moedas paralelas são sistemas econômicos intencionalmente criados para fazer face aos problemas e limitações gerados pelas moedas oficiais, sejam elas nacionais ou globais (Linton; Soutar, 1994).

A questão acerca da premência do desenvolvimento local ressurge de modo concomitante à globalização, processo demasiadamente estudado e, entrementes, de facetas ainda desconhecidas. Segundo Swyngedouw (1989), o processo de globalização incorre na reconstrução da localidade, que atinge diversos domínios, dentre eles: a barganha entre trabalhadores e capitalistas, que deixa de ser mediada pelo Estado e passa a incidir na firma ou localmente; a substituição de políticas redistributivas, antes nacionais, por um sistema privado e individual, o que abre espaço para o aumento das desigualdades sociais e espaciais; a mudança de um Estado intervencionista para um Estado simplesmente regulador.

Albagli (1999), por seu turno, contextualiza as diferenças entre duas visões da globalização: a "desterritorialização" versus a "reinvenção do local". Claramente, se posiciona favoravelmente à segunda percepção, mostrando que o cenário para a análise do local é a globalização, fenômeno de "alongamento das relações entre o local/presente e o distante/ausente" (p. 185). Em vez de aventar o fim do Estado-nação, a autora fala da transformação do seu papel, que passa a ser o de importante intermediador de interesses de diversos âmbitos (global, nacional, local). Não obstante, o local passa a ser um "espaço privilegiado de resistência" (p. 190) aos poderosos interesses do capital.

Amim e Thrift (1994) entendem que não há por que se imaginar que o global ameaça a existência do local. Os locais são o palco das relações sociais e são construídos por elas. São importantes na produção pois permitem a integração social e cultural e o contato físico, desafiando o que é global com suas especificidades, lutas, culturas. Leyshon e Lee (2003) lembram que é preciso considerar que o desenvolvimento econômico e social não se dá de maneira linear 
no tempo e no espaço, e sim de modo proliferativo. Segundo esses autores, existem inúmeras formas locais de organização que convivem com o capitalismo global, algumas opositoras a ele, outras não.

De acordo com Lee (1999), em complemento à globalização vem ocorrendo um processo de universalização da moeda. Ele argumenta que o desenvolvimento de moedas universais, resultado da convergência entre diferentes moedas nacionais com a finalidade de expandir o espaço geográfico de trocas, causou a erosão de sistemas de valorização baseados no local e a concomitante imposição de medidas de valor e troca baseadas externamente. A moeda global, segundo esse autor, retira a autonomia econômica do local, ao mesmo tempo em que desvincula as relações de oferta e demanda do lugar. Segundo essa perspectiva, a construção de uma moeda local recupera a capacidade dos agentes de influenciar a acumulação econômica e a reprodução social no espaço em que vivem.

Com a convicção de que a moeda é socialmente construída no espaço, Lee (1999) afirma que a moeda é o mais geográfico dos fenômenos econômicos. Ela permite a produção econômica e a reprodução social no tempo e no espaço. É com esse pano de fundo que partimos agora para o aprofundamento da compreensão acerca do fenômeno das moedas locais.

\section{Sistema de moedas locais}

\subsection{Antecedentes}

A ideia da delimitação do uso da moeda no espaço ou por grupos não é nova. As 'paramoedas' são um claro exemplo: tickets-refeição, milhas de companhias aéreas, vales-transporte, etc. Elas são definidas por Blanc (1999) como todos aqueles instrumentos utilizados como meio de conta e de pagamento e que convivem paralelamente às moedas nacionais, mas sem concorrer com estas, apenas as complementando. Sua validade é limitada, a priori, seja por um certo conjunto de bens e serviços ou pessoas, seja por um espaço específico ou fixada em um horizonte temporal dado.

Essa ideia encontra respaldo na teoria econômica. Interessante registrar a contribuição de Robert Mundell (1968), com suas formulações a respeito das áreas monetárias ótimas (optimum currency areas). Conforme sua teoria, nem sempre existe mobilidade de capital e trabalho entre regiões de um mesmo país, o que gera taxas distintas de desemprego e inflação para cada uma delas: a mudança na demanda pelos produtos de uma região provavelmente induz a mudanças na direção oposta em outras regiões, e políticas de estabilização nacionais não são capazes de neutralizar completamente esses efeitos entre regiões. O ideal, logo, seria que o mundo fosse dividido em regiões economicamente uniformes, cada 
qual com sua própria moeda, tal que houvesse mobilidade de fatores intrarregiões e imobilidade entre as mesmas. Como levanta o autor, nem sempre essas regiões coincidem com as áreas correspondentes aos países, daí a dificuldade política de se colocar em prática este argumento.

A teoria econômica e seus pressupostos sobre o "homus economicus" foi também utilizada por Schraven (2001b) para analisar as vantagens de uma moeda própria a uma comunidade. Ele adverte que não é a política monetária e sim as exportações líquidas que garantem a liquidez das regiões. Se uma região incorre em déficit, a moeda é drenada para outras regiões, e a redução da disponibilidade de moeda leva ao aumento dos custos de procura, informação e transação, o que, por sua ordem, causa redução no montante de bens e serviços trocados. A consequência, assim, é uma distribuição subótima das trocas potenciais. Conclui seu estudo afirmando que a oferta descentralizada de moeda permite um ajuste mais flexível a choques e reduz falhas de predição em que incidem as autoridades monetárias.

Lieater (2001) lembra as contribuições de Silvio Gesell, um economista alemão e naturalizado argentino, que nos anos 1930 defendia o uso de uma moeda selada, que teria validade no tempo e restrição espacial. Keynes (1964 [1936]) também fez referência à teoria de Gesell que, segundo ele, caiu em um ostracismo injustificado. A ideia era, grosso modo, criar uma moeda com data de vencimento predeterminada, quando então seria necessário o pagamento de uma taxa para continuar valendo, o que incentivaria a circulação em detrimento da poupança. É chamada de moeda selada ou oxidável porque requereria a compra periódica de uma espécie de selo, caso contrário seria invalidada. As pessoas a usariam para consumo e não para acumulação, pois neste último caso arcariam com o ônus da taxa, que equivale, na prática, a juros negativos. Algumas cidades de países que passaram por forte crise nessa época, tais como Alemanha, Áustria e Estados Unidos, ${ }^{5}$ tiveram experiências auspiciosas neste sentido mas que vigoraram por pouco tempo, devido à proibição dos governos centrais, tementes de que houvesse perda do poder sobre a moeda.

Jane Jacobs (1984) é outra importante autora a tratar, seminalmente, da questão da moeda limitada no espaço. Em sua construção teórica, ela aponta para a substituição de importações, em outras palavras, a diversificação da economia, como a única saída para o desenvolvimento econômico de um lugar. A especialização em poucos setores voltados para exportação torna a economia frágil e excessivamente dependente de importações, deixando-a mais vulnerável a crises

(5) Irving Fisher foi um grande defensor do uso deste tipo de moeda nos Estados Unidos durante a Grande Depressão, o que não foi levado à prática por causa da posição contrária do governo, na figura do presidente Roosevelt, que no discurso de apresentação do New Deal vetou qualquer utilização de "emergency currencies" (moedas emergenciais) (Lieater, 2001, p. 157). 
devastadoras. A autora defende que as moedas nacionais ou imperiais são fator de desestabilização para as economias locais - opinião que se assemelha à discussão feita por Mundell (1969) - pois não são um bom mecanismo de ajuste da economia local, já que carregam informações sobre o comércio da nação como um todo em relação ao exterior, desconsiderando variações internas e o comércio entre as regiões do mesmo país. A realidade do comércio das cidades, que pode ser bastante contrastante internamente, fica sujeita a um mecanismo único de ajuste. Ela faz uma analogia com um sistema orgânico imaginário, supondo que várias pessoas, de diferentes tamanhos e idades, estejam ligadas a um mesmo sistema respiratório. Sendo as necessidades de oxigênio diferentes, variando de acordo com muitos fatores, dentre eles a atividade que realiza cada pessoa, como dormir ou fazer esportes, o resultado de tal sistema pode ser devastador para alguns.

De forma similar, as economias locais necessitam de diferentes correções em momentos distintos no tempo. Cada cidade, afirma Jacobs (1984), tem seu próprio ritmo para substituir as importações e gerar exportações que ela chama de inovativas. Se suas exportações estão em declínio, a cidade precisa de uma moeda que se desvalorize para encarecer os produtos produzidos externamente e assim incentivar o processo de substituições de importações.

Jacobs enfatiza que a evolução das telecomunicações tende a superar as inconveniências e dificuldades técnicas de se multiplicar a quantidade de moedas, mas reconhece que sua sugestão teórica é de difícil imposição devido à força das nações, construída historicamente. Como coloca Primavera (2003, p. 10), a moeda é símbolo de soberania: "Compartilhar uma moeda comum cria uma fronteira informativa invisível, mas muito efetiva, entre "nós' e 'eles"”. 6 Daí as desvantagens da implantação de moedas regionais em caráter oficial.

Apesar de não serem oficiais, as moedas locais não precisam ser encaradas como ilegais. Lieater (2001) recorda que a maioria dos países não possui legislação que impeça a existência de um acordo comunitário para o uso de um meio de troca próprio. O que há é a definição do monopólio legal da moeda corrente sob supervisão dos bancos centrais, o que segundo o autor significa em termos pragmáticos que não se pode forçar ninguém a usar qualquer tipo de meio de pagamento que não seja o oficial para o pagamento de dívidas, taxas e impostos. Fica claro, pois, que as moedas nacionais e as locais não são excludentes e que a moeda local, exatamente por suas limitações, não representa ameaça à hegemonia das moedas nacionais. As moedas locais existentes são microexperiências de abrangência espacial e econômica limitada.

Tendo visto as ideias de alguns teóricos que respaldaram o uso de moedas locais e enfatizada a diferença entre as moedas locais e nacionais, passamos à

(6) Tradução nossa. 
Sistemas de moeda local: uma investigação sobre seus potenciais a partir do caso do Banco Bem em Vitória/ES

descrição de suas características principais e das práticas existentes contemporaneamente ao redor do mundo.

\subsection{Sistemas de moeda local}

A literatura internacional recente tem como foco, grosso modo, as experiências de moeda local chamadas de Lets (Local Exchange and Trading Systems), já que são estas as de maior número. Como esse é um sistema com características específicas, que o diferenciam de outras variações existentes, como os Clubes de Trocas preconizados na Argentina ou os SEL (Systèmes d'Échange Local) da França, utilizamos neste trabalho uma denominação própria, Sistemas de Moeda Local (SML), para tratar de modo mais amplo esse fenômeno.

A intenção é dar maior destaque às características comuns a todos os SML para extrair a essência da experiência de uso de moeda paralela. Sua definição mais clara e concisa pode ser extraída de Lieater (2001): trata-se de um acordo entre pessoas de uma mesma comunidade para o uso de uma moeda coexistente com a nacional como meio de pagamento local. Sucintamente, os aspectos mais importantes dessas moedas são: i) iniciam-se no terceiro setor, isto é, fora do Estado e do mercado capitalista; ii) têm restrição do uso no espaço e iii) inexiste a incidência de juros.

Em tais circuitos, uma moeda local, muitas vezes também denominada moeda social, paralela ou complementar, é criada internamente e o seu valor é estipulado, mais comumente, pela correspondência com a moeda nacional, por ser a forma mais fácil de ser abarcada pelos seus usuários. Não se tem notícia da existência de moedas locais cuja conversibilidade oscile atinente a uma taxa de câmbio entre elas, de acordo com os ideais lançados por Mundell e Jacobs, já citados acima. A relação entre a moeda local e a nacional, quando existente, é sempre fixa, estabelecida ad hoc. Essa é outra limitação que a diferencia da moeda nacional e consolida a constatação de que as moedas locais não têm por finalidade suprimir as nacionais.

Outro princípio fundamental é que a moeda criada pela comunidade não seja utilizada para transacionar com ativos que rendam juros, para que não se transformem em meio de acumulação. Respaldo a essa ideia pode ser buscado na teoria baseada em Keynes (1964 [1936]). Carvalho et al. (2000) explicam que ele descreve a economia monetária de produção como comportando a existência de duas esferas de circulação da moeda: uma produtiva e outra financeira. Na circulação produtiva, "a moeda exerce a sua função de meio de troca, faz girar bens e serviços" (op. cit., p. 169), enquanto na esfera da circulação financeira a moeda se transforma em um ativo que gera ganhos sem levar a crescimento econômico real, é percebida como um "fim em si mesmo". Sem rendimentos, não há incentivos para que a moeda saia do circuito produtivo, o que é uma proposta 
essencial dos SML e impõe a eles uma característica completamente distinta do sistema financeiro convencional.

No sistema capitalista, a produção da moeda, distintamente das demais mercadorias, é inelástica porquanto é controlada pela autoridade monetária e sua elasticidade de substituição é nula, o que, qual argumentado por Keynes (1964 [1936]), torna os juros resistentes à baixa diante de um aumento da sua demanda. Outrossim, a baixa elasticidade de substituição está ligada ao fato de ser a moeda o padrão para contratos e salários: “(...) há uma vantagem manifesta em conservar bens no mesmo padrão em que irão vencer-se os compromissos futuros" (op. cit., p. 228). Logo, essas duas características da moeda, juntamente com a existência de preferência pela liquidez, definem a taxa monetária de juros. Um aumento nessa taxa retarda a produção de riqueza em outros ramos da economia. À medida que se torna mais vantajoso aos empresários deixar de produzir e aplicar seu capital no mercado financeiro, as taxas de juros são um forte fator de desemprego. A dinâmica econômica é descrita caricaturalmente por Keynes da seguinte forma:

(...) o desemprego prospera porque as pessoas querem a lua; - os homens não podem conseguir emprego quando o objeto de seus desejos (ou seja, o dinheiro) é uma coisa que não se produz e cuja demanda não pode ser facilmente contida. $\mathrm{O}$ único remédio consiste em persuadir o público de que lua e queijo são praticamente a mesma coisa, e fazer funcionar uma fábrica de queijo (que é o mesmo que dizer um banco central) sob a direção do poder público (Keynes, 1964 [1936], p. 227).

Podemos dizer, por conseguinte, que as moedas locais oferecem, mesmo que com limitações, uma forma de substituir a moeda-padrão por outra, de maneira informal e restrita no tempo e no espaço. Como se verá com mais minúcia posteriormente, em alguns casos de SML a criação de moeda deixa de ser controlada pela autoridade estatal, o que retira da moeda a característica de inelasticidade da oferta. Essa é, precisamente, a situação dos Lets. Em outros casos, como o dos bancos comunitários no Brasil que serão vistos adiante, a oferta é controlada, mesmo que indiretamente, pelo Bacen e nesse caso é a imposição de ausência de taxa de juros que impede a utilização da moeda como ativo. Nesta última experiência, a principal preeminência advém da possibilidade de acesso sem ônus à moeda para realizar transações e da restrição de sua validade a um espaço desprivilegiado economicamente, em relação a outras regiões.

Mais uma vez, cabe realçar que as vantagens da moeda local devem ser vislumbradas sempre partindo do pressuposto de que as moedas nacionais permanecem essenciais ao funcionamento da economia capitalista. Schraven (2000) levanta que, do ponto de vista econômico, a criação de uma moeda própria não tem como meta a autossuficiência da oferta local, mas o incremento da capacidade de autofomento. Tampouco tem a finalidade de substituir a moeda nacional, que continua sendo imprescindível à realização das importações do local. 
Tal como argumenta Jacobs (1984), a substituição de importações não tem como intuito o fim das trocas de um lugar com o outro, apenas leva à possibilidade de diversificar o consumo, produzindo o que antes era importado e importando novos produtos e serviços.

A priorização das trocas locais faz com que diminua a dependência com relação à economia de outros lugares. A ativação de capacidades produtivas se dá de maneira mais sustentável, se comparada à prática de injeção de capital na região, bastante comum em políticas regionais. Para Purdue et al. (1997), a criação de moedas locais pode ser encarada como uma espécie de "microkeynesianismo", em que a preocupação maior é com a proteção da economia local. Quanto mais se gasta internamente, maior é o multiplicador.

É importante salientar também, como característica fundamental dos SML, que é imprescindível que os agentes tenham confiança em sua existência. O valor monetário só se sustenta por meio da confiança. Quanto mais global for a moeda, maior a necessidade de poder estatal e leis regulatórias para garantir essa confiabilidade. Por outro lado, as moedas locais precisam existir em meio a uma aceitação social, o que se viabiliza desde a própria escolha do nome da moeda até a formação de uma identidade da comunidade com o local em que vive (Lee, 1996). Em outras palavras, é essencial que haja coesão social. Laascher (1999) afirma que, nos SML, obter a moeda é mais do que ganhar acesso ao pagamento e à aquisição de bens, é engendrar também um contrato de confiança, que na maioria das vezes é informal.

Ademais, vale ressaltar que a perspectiva adotada aqui, além de se pautar no referencial pós-keynesiano, vai também ao encontro do que se pode chamar de teoria monetária marxista. ${ }^{7}$ Carvalho (1986) elucida que, com seu método lógicohistórico, Marx rejeita leis imutáveis:

Ao invés do agente racional walrasiano, suspenso no tempo e no espaço, os agentes econômicos em Marx têm motivações e comportamentos historicamente determinados, evoluindo e se alterando com a sucessão de formas de organização social. Por esta razão, conceitos como moeda, apesar de presentes em várias fases históricas, têm significados diferentes em cada uma delas. Para Marx, conceitos como produção e moeda apenas adquirem seu pleno potencial explicativo quando localizados historicamente (Carvalho, 1986, p. 7).

Fica evidente, dessa maneira, que dentro dessa visão a moeda é percebida como portadora de informações, normas e valores. Tais informações se referem à

(7) Segundo Carvalho (1986), não foi a intenção de Marx construir uma teoria monetária. A proposta desse autor é apenas assinalar a possibilidade de se vislumbrarem elementos existentes em Marx que possibilitam a construção de uma tal teoria: "Marx, como Keynes, recusou a dicotomia real x monetário e lançou as bases para uma teoria monetária bastante similar à de Keynes" (p. 6). 
extensão temporal e espacial em que podem ser efetuadas as transações. Assim, tal visão respalda as vantagens da utilização de moedas locais.

Por fim, é necessário esclarecer que, entre os estudiosos desse fenômeno, é patente a constatação de que os benefícios gerados pela criação de moedas paralelas não são facilmente mensurados quantitativamente, por meio de simples medições de consumo, emprego e produto, pois englobam inúmeras outras melhorias qualitativas como construção de um senso de comunidade, aumento da 'empregabilidade', por intermédio da interação social e da aquisição de habilidades práticas, e crescimento da autoconfiança individual e coletiva. Como estão à margem da economia e se trata de fenômenos microespaciais, os SML não são considerados relevantes em termos de valor movimentado.

Descritas as características gerais dos SML, listaremos agora de maneira concisa as experiências mais conhecidas pelo mundo. Como já dito, é nos Lets (Local Exchange and Trading Systems) que se baseia a majoritária parte da literatura que trata do tema. A primeira experiência de Lets conhecida se deu no ano de 1983, no Canadá, em uma vila próxima a Vancouver onde teve início uma crise econômica devido à transferência de uma base aérea para outra região (Búrigo, 2001). No início deste século, Lieater (2001) estimou que existiam por volta de 2.500 Lets espalhados pelo mundo. Esses sistemas existem, sobretudo, na Inglaterra e no Canadá, mas também ocorrem em diversos outros países, em sua maioria desenvolvidos.

O sistema funciona da seguinte forma: pessoas moradoras de um mesmo bairro, cidade ou região se associam para criar uma rede de troca de serviços e bens onde será utilizada uma moeda própria. Cada um informa qual é o serviço ou o bem que oferece: aulas de culinária, assessoria em informática, jardinagem, consultas médicas, aluguéis, entre outros inúmeros itens e atividades. Todos possuem uma conta com seu saldo em moeda local, que na maioria das vezes existe apenas virtualmente, para que a pessoa que recebeu um serviço ou comprou um bem obtenha o débito no valor equivalente enquanto a que ofertou receba o crédito no mesmo valor. Nos Lets, existe uma administração central que contabiliza as transações, funcionando na prática como uma espécie de banco informal (Lieater, 2001). Ademais, a moeda local funciona como um elemento de articulação entre a demanda e a oferta, uma vez que existe um esforço por parte dos membros em divulgar regularmente os bens e serviços disponíveis na economia local.

Uma outra característica cara aos Lets é a forma pública como é divulgado o balanço de créditos e débitos efetuados, com a finalidade de construir confiança entre seus membros e evitar os chamados "free-riders", ou "caronas", cuja intenção seria apenas usufruir os bens e serviços disponíveis no sistema, sem 
oferecer nada em troca (Purdue et al., 1997; Pacione, 1997). Em termos microeconômicos neoclássicos, o agente teria incentivos para se recusar a pagar seus débitos (o que significa não ofertar nada) pois enquanto o seu benefício diante de tal atitude é totalmente individual, o prejuízo é repartido coletivamente, sendo diluído. Schraven (2001b), contudo, enfatiza que existem aspectos institucionais dos Lets que garantem sua sustentabilidade. Pelo fato de se tratar de uma construção social local, os Lets encerram uma dimensão coesa e tácita de comprometimento que advém da chamada "cooperação quase voluntária", isto é, mesmo sem um compromisso explícito e formal, os agentes não trapaceiam, pois, caso o fizessem, se submeteriam a um constrangimento social e a uma punição moral (Schraven, 2001a).

Outra experiência de moeda local, distinta dos Lets, são os Time Dollars (TD), circulantes por intermédio dos chamados Bancos de Horas. Essa moeda opera com o princípio de equivalência com a hora do serviço, não importando o seu tipo ou sua complexidade. Esse modelo de SML surgiu nos Estados Unidos em 1980 com a intenção de fomentar a solidariedade entre pessoas viventes em um mesmo bairro. As trocas se concentram basicamente em serviços como o de babá, assistência a idosos, aulas particulares e pequenos reparos domésticos. Edgar Cahn (2001), fundador do sistema, afirma que a ideia surgiu como uma tentativa de amenizar os cortes crescentes de gastos governamentais com o bem-estar social.

Grosso modo, ao analisar a literatura aqui empregada, percebe-se que não é invariavelmente a finalidade econômica que permeia a criação dessas comunidades, mas muitas vezes a crença na necessidade de construir relações sociais amparadas em paradigmas distintos de valores como consumismo e individualismo. É patente, contudo, a diferença entre essas experiências em países desenvolvidos e as conhecidas nos países subdesenvolvidos. É fácil perceber que, neste último caso, o fenômeno sempre está diretamente associado à existência de depressão ou estagnação econômica.

Em meados dos anos 1990, em meio à forte crise econômica, foi preconizado um fenômeno na Argentina que se espalhou por todo o país: a formação dos Clubes de Troca (CT). No início, eram basicamente trocas típicas de escambo, surgidas exatamente quando o colapso financeiro originou uma forte redução do dinheiro disponível, inclusive havendo congelamento das contas bancárias. Gradualmente, moedas foram sendo criadas (Cato, 2006). Nos CTs, as pessoas se organizam para realizar feiras onde oferecem o que produzem, como artesanato, alimentos, vestuário, ou mesmo o que não produzem mas querem trocar, como eletrodomésticos, utensílios ou vestimentas usados. Cada integrante recebe igualmente um valor estipulado em moeda própria, que usam para comprar na feira. Sendo assim, diferentemente dos Lets, nos CTs as trocas têm hora e local 
definidos e as moedas existem sempre em meio físico. São considerados o maior e mais rápido caso de surgimento de moedas complementares, atingindo $7 \%$ da população total do país e com um ciclo de vida que durou cerca de apenas 8 anos (Silva, 2005). Primavera (2003) destaca que em 2001 havia mais de cinco mil CTs ativos no país, e foi essa explosão de maneira precipitada que causou a derrocada de muitos dos clubes, devido a problemas como falsificação de notas e falta de controle sobre a emissão.

Já no Brasil, um levantamento preliminar foi suficiente para, mais uma vez, detectar a origem distinta, em relação ao que acontece nos países desenvolvidos, de seus SML, cuja ocorrência é ainda mais recente, essencialmente a partir do ano de 2000. Em alguns casos, os SML brasileiros se assemelham aos CTs argentinos. É nesse esquema que funcionam, por exemplo, a comunidade de Rubem Berta, em Porto Alegre (cuja moeda, o rubi, foi avaliada em um trabalho acadêmico por Silva, 2005), o Clube de Trocas Novo Alvorecer, em Curitiba-PR, o Grupo do Jardim Rubilene, em São Paulo-SP e o Grupo de Economia Popular e Solidária (Geps) em Vitória da Conquista-BA (PACS, 2005).

O outro tipo de SML bastante marcante no Brasil, e que é o foco do nosso estudo de caso, é concernente aos Bancos Comunitários. Esse projeto envolve diversas atividades, dentre elas microcrédito e capacitação profissional. Uma delas, a que mais interessa a este estudo, é a criação da "Moeda Social" ou "Circulante Local". Atualmente, estes bancos existem já em atuação em seis lugares: Fortaleza-CE, Santana do Acaraú-CE, Paracuru-CE, Palmácia-CE, Simões Filho-BA, Vila Velha-ES e Vitória-ES (RBC, 2006). Este último caso foi objeto de atenção mais minuciosa e será tratado adiante.

Os Bancos Comunitários possuem como definidoras as características seguintes, sistematizadas pelos seus próprios idealizadores: i) são criados a partir da iniciativa da própria comunidade; ii) realizam empréstimos tanto em reais quanto em moeda social; iii) atuam em locais marcados por pobreza e desigualdade social; iv) têm sua sustentabilidade financeira garantida por financiamentos, subsídios e/ou doações, sejam elas do setor público ou do privado (RBC, 2006).

Esses bancos trabalham com várias linhas de microcrédito: produtivo, para o consumo e para reforma de habitação. Suas taxas de juros encontram-se sempre abaixo das cotações do mercado, sendo que os empréstimos feitos com a moeda paralela são isentos de juros; cobra-se apenas uma taxa com o objetivo de cobrir despesas com a CPMF. A principal exigência para concessão de empréstimos é que a pessoa seja moradora do local. A avaliação dos pedidos de crédito é feita de forma alternativa, por intermédio de visitas e consulta à rede de vizinhos do demandante e análise técnica da proposta, não havendo averiguações nos sistemas 
convencionais como SPC e Serasa. Percebe-se que o caráter local destes bancos comunitários faz com que diminua a exclusão financeira das comunidades onde estão inseridos, uma vez que a proximidade aumenta a confiança no sistema e diminui a ocorrência de inadimplência, o que eleva a possibilidade de ofertar mais serviços financeiros.

A moeda apresenta, por sua vez, algumas particularidades: i) possui lastro em reais, que ficam depositados em alguma instituição financeira formal, só sendo retirados quando se precisa trocar a moeda social por reais; ii) é produzida com componentes de segurança; iii) a circulação é livre no comércio local; iv) a conversão de reais em moeda social é feita sem restrições e a conversão no sentido contrário pode ser feita desde que observadas algumas imposições, definidas por cada banco, separadamente.

A necessidade de lastro total em reais advém de uma exigência do Banco Central. Dessa forma, controla-se a proliferação de meios de pagamento paralelos ao oficial e impede-se que exista criação de moeda e a suposta possibilidade de tendências inflacionárias. Por outro lado, esse artifício reduz também o potencial multiplicador da moeda. Além dos meios já citados para o lastro, como a troca voluntária de reais por moeda social e o pagamento de salários, as principais fontes que permitem a injeção das moedas locais no circuito são a doação de pessoas físicas ou jurídicas e a transferência de recursos por parte de governos de todas as esferas.

Existem quatro vias de escoamento da moeda social: i) os empréstimos, ii) a oferta de troco em moeda local pelo vendedor, iii) o pagamento de parte do salário nessa moeda conforme comum acordo, nos estabelecimentos locais, e iv) a troca espontânea, realizada no banco comunitário, de reais por essas moedas por parte de qualquer interessado em suas vantagens. Realça-se que, para que todos esses fluxos existam, é imprescindível que a comunidade tenha confiança na moeda social e que haja uma consciência em prol da necessidade de fomentar a economia local.

A ideia de criar uma moeda com validade restrita ao local tem como finalidade principal o fortalecimento da economia do lugar, já que é imposto um compromisso de que o consumo ocorra ali, o que, em termos keynesianos, gera um aumento do multiplicador interno. Garantir que seja possível trocar a moeda social pela moeda nacional é importante para manter a confiança no sistema e não impedir o relacionamento da economia local com o mercado "externo". Para encorajar, opostamente, a conversão do real para a moeda local e, por conseguinte, aumentar seu trânsito no território, os bancos fazem uma campanha de conscientização sobre sua importância, e os comércios que aderem ao sistema são incentivados a oferecer descontos quando a moeda local é utilizada, o que induz 
ainda mais o consumidor a desejar servir-se dela. A contrapartida esperada pelos vendedores com essa estratégia de redução dos preços em moeda paralela é a 'fidelização' de clientes e o decorrente aumento das vendas. Os comerciantes interessados se cadastram para receber a moeda e afixam um aviso de aceite em seu estabelecimento.

É imperativo dar vulto ao fato de que, apesar de existirem bem definidas algumas características dos bancos comunitários e da moeda social, frutos de um esforço de sistematizar os fenômenos acontecidos pelo país afora, cada experiência é única, posto que é um processo em constante construção. Vistas, portanto, as características gerais dos Bancos Comunitários do Brasil, nos dedicaremos a seguir ao caso pesquisado em particular.

\section{0 estudo de caso}

Realizamos, em agosto de 2006, uma visita aos dois únicos Bancos Comunitários existentes na região Sudeste, ambos no Estado do Espírito Santo: o Banco Bem, em Vitória, e o Banco Terra, em Vila Velha. Dentre esses, optou-se por aprofundar a investigação do primeiro, onde foram coletadas informações e realizadas entrevistas com os usuários da moeda local.

Vitória possuía, em 2000, 292.304 habitantes e 83.517 domicílios. O Banco Bem atua em três bairros da capital: São Benedito (de onde deriva o nome do banco e onde se localiza a sua sede), Itararé e bairro da Penha. Em 2000, a população desses três bairros somados era de 15.600 pessoas (5,3\% da população da capital) e eram 3.493 domicílios ao todo (4\% dos domicílios de Vitória). Esses três bairros se concentram em área de menos de $1 \mathrm{~km}^{2}$ e de encostas íngremes, dando forma a uma aglomeração bastante típica dos "morros" ou "favelas". Algumas áreas são de acesso extremamente difícil, e ali se verificam condições de moradia bastante precárias (Vitória, 2004). Foi observada também a distância das agências bancárias. Nenhum dos três bairros as possui, e a agência mais próxima é de um banco público, a Caixa Econômica Federal (CEF). Somente na própria sede do Banco Bem, localizada no alto do Morro São Benedito, é que recentemente foi implantado um correspondente bancário da CEF.

Na Tabela 1, a seguir, vemos que o rendimento médio mensal dos responsáveis por domicílios para os três bairros era em 2000 de apenas R \$ 394,93. Para toda a cidade de Vitória, esse valor era de R \$ 1.286,38. Fica claro, assim, que se trata de regiões bastante desfavorecidas. 
Sistemas de moeda local: uma investigação sobre seus potenciais a partir do caso do Banco Bem em Vitória/ES

Tabela 1

Rendimento médio nominal mensal das pessoas responsáveis pelos domicílios particulares permanentes por sexo

\begin{tabular}{l|c|c|c}
\hline \multirow{2}{*}{\multicolumn{1}{c|}{ Bairros }} & \multicolumn{3}{|c}{$\begin{array}{c}\text { Rendimento médio nominal mensal } \\
\text { (em Reais) }\end{array}$} \\
\cline { 2 - 4 } & Homens & Mulheres & Total \\
\hline Itararé & 636,64 & 342,85 & 534,25 \\
\hline Bairro da Penha & 498,77 & 313,00 & 430,80 \\
\hline São Benedito & 234,07 & 180,73 & 219,73 \\
\hline Total & 456,49 & 278,86 & 394,93 \\
\hline
\end{tabular}

Fonte: Censo (2000). Prefeitura de Vitória.

O Banco Bem existe desde outubro de 2005 e a sua moeda própria foi implantada em fevereiro de 2006. O banco se constitui juridicamente como uma Oscip (Organização da Sociedade Civil de Interesse Público) e é gerido pela Associação de Artesãos Ateliê de Ideias que, além do microcrédito, oferece cursos de capacitação profissional, promove feiras de economia solidária e atualmente engloba cinco grupos produtivos (artesanato, marcenaria, confecção de roupas, culinária e fabricação de materiais de limpeza). Todos os grupos são compostos por moradores dos bairros que se encontram à margem da economia e da sociedade. São, ao todo, 38 pessoas trabalhando nos moldes da economia solidária, com repartição igualitária de tarefas e lucros.

O limite para empréstimos em bens (B \$) é de 100 unidades monetárias, desprovidos de juros e pagáveis em até duas vezes. Entre outubro de 2005 e junho de 2006, a coordenação aponta a concessão de empréstimos no valor de B\$ 2.241,50 (bens - crédito para consumo) e $\mathrm{R} \$ 45.647,90$ (reais - crédito produtivo e para reformas). Até a data de realização da visita ao local, 29 pessoas tinham tomado empréstimo em bens. Os comerciantes precisam acumular um mínimo de B \$ 500 para trocá-los por reais na sede do banco e a taxa de administração cobrada é de $0,5 \%$. São 38 estabelecimentos comerciais e prestadores de serviços cadastrados.

Quanto às entrevistas realizadas, a intenção foi engendrar uma pesquisa qualitativa. As perguntas objetivaram captar opiniões, o que é certamente algo subjetivo, mas isso não invalida o nosso propósito que é genuinamente exploratório. A novidade do uso de moeda local e a precariedade dos dados não permitem conclusões inequívocas nem análises puramente objetivas de resultados.

Foram empregados dois tipos de questionário: um para os consumidores da moeda bem e outro para os receptores da moeda, ou seja, os vendedores locais. As entrevistas foram individuais e concebidas nas residências das pessoas ou nos estabelecimentos comerciais. Quanto à metodologia adotada, é preciso estar atento às limitações desse tipo de averiguação, pois o objetivo é abordar realidades pouco 
conhecidas pelo pesquisador, o que o impede de realizar generalizações. Outro cuidado diz respeito à possibilidade de criar distorções, seja através da interpretação subjetiva do pesquisador, seja por ocultação de informações por parte do objeto.

No que concerne aos consumidores, a população objeto de estudo foi calculada em 53 pessoas. A amostra entrevistada equivaleu a 35\% dessa população, o que corresponde a 19 pessoas, escolhidas através do cadastro de clientes do banco, de acordo com a possibilidade de serem encontradas durante a semana em que visitamos o banco. Essa dificuldade de localizar os potenciais entrevistados se deveu à grande quantidade de pessoas que não possuíam telefone e que estavam ausentes de suas residências durante o dia por estarem trabalhando. Sendo assim, a situação dos entrevistados se dividiu da seguinte maneira: 13 pessoas trabalhavam no próprio bairro, 2 estavam desempregadas, 1 era aposentada e 3 eram trabalhadores informais, como diaristas ou vendedores ambulantes, que não possuem horário e dia de trabalho fixos e, portanto, podiam ser encontrados em casa. Ressaltamos, pois, que a amostra possui esse relevante viés.

Foram entrevistadas 19 pessoas - 18 mulheres e apenas um homem. Por um lado, isso reflete o papel preponderante da mulher tanto nos grupos produtivos quanto na tomada de empréstimos para consumo, que normalmente são demandados para comprar alimentos e outros produtos de primeira necessidade para a família. De outro lado, isso é também um resultado do viés referido acima, já que, como se sabe, as mulheres estão mais sujeitas à exclusão e a trabalhos informais e/ou domésticos.

O nível de estudo é, de modo geral, baixo: estudaram só até a quarta série 6 pessoas. Além disso, somente 6 pessoas completaram o Ensino Fundamental (até a $8^{\text {a }}$ série) e apenas 3 das 19 pessoas concluíram o ensino básico (que compreende o Ensino Fundamental e o Ensino Médio). Nenhuma delas passou ao Ensino Superior.

Sobre a asserção dos entrevistados relativa ao lançamento da moeda, todas as percepções se mostraram positivas (13 disseram que foi uma ótima ideia e 6 afirmaram ser uma boa ideia), e sempre após a pergunta se seguiam comentários espontâneos sobre o potencial de melhoria das condições de vida que a moeda bem pode proporcionar. A principal vantagem percebida na existência de uma moeda própria do local foi a possibilidade de descontos nas compras com tal moeda, apontada por 18 pessoas, o que incute a ideia de que são fundamentais os incentivos positivos para a consolidação de um SML. Dez entrevistados mostraram ter consciência das vantagens que a moeda pode trazer para a economia dos bairros, além de ter sido mencionada também a melhoria da qualidade de vida ( 2 respostas) e do relacionamento pessoal na comunidade (4 respostas). 
O volume da moeda bem que é manuseado mensalmente pelos entrevistados é pequeno: média de B \$ 35,00 (trinta e cinco bens) por pessoa. Isso está diretamente ligado ao baixo rendimento dos entrevistados: 6 auferiam menos do que R\$200,00 mensais, 9 afirmaram ter renda entre $\mathrm{R} \$ 200,00$ e $\mathrm{R} \$ 500,00$ e somente 4 ganhavam de $\mathrm{R} \$ 500,00$ até $\mathrm{R} \$ 800,00$. Dessa observação, segue-se que o impacto econômico da moeda local, se mensurado quantitativamente, se mostrará bastante tímido, algo que já foi evidenciado em alguns estudos de SML, dentre eles os Lets, como já citamos no capítulo anterior. De fato, durante as entrevistas, foi possível notar que o impacto da moeda só pode ser captado de forma subjetiva quando conhecemos a realidade de pobreza e privação a que estão submetidos os moradores desses bairros. Afora isso, vale relembrar que o volume total de bens em circulação é, por si só, ainda reduzido, posto que são apenas seis meses desde o seu lançamento (fev./2006) até o acontecimento da pesquisa (ago./2006).

Ressalte-se que muitos dos valores declarados são somente uma média estimada da renda, que é, para alguns, devido ao desemprego ou à informalidade, bastante variável e incerta. Quatro respondentes incluíram no cálculo os valores recebidos pelo Bolsa Família. Aliás, um evento de extrema importância para a ampliação do circuito da moeda será a efetivação do acordo já celebrado entre o Banco Bem e a CEF que possibilitará aos beneficiados com a Bolsa Família que recebam uma parte desse valor em bens, caso queiram.

No tocante ao acesso ao sistema financeiro tradicional, 10 entrevistados não possuem nenhum tipo de vínculo, e dentre os 9 que possuem, esse vínculo se limita à posse de conta corrente ou poupança. Quanto aos empréstimos, observamos que a maioria - 13 pessoas - diz nunca tê-los demandado no sistema financeiro convencional. As que o fizeram, priorizaram os bancos públicos e as financeiras (formalmente chamadas de SCFI - Sociedades de Crédito, Financiamento e Investimento). Estas últimas, geralmente, oferecem crédito a juros acima dos que praticam os bancos comerciais, no entanto facilitam a obtenção porque fazem menos exigências. Conserva-se, portanto, amparada a hipótese central do presente trabalho: o público-alvo desta pesquisa está sujeito à exclusão financeira, muitos estando completamente desprovidos de qualquer tipo de serviço, outros tendo à disposição apenas os serviços mais simples.

A maioria assinalou ter dificuldades de acesso aos bancos: 14 respostas. É valioso relatar que todas as 5 pessoas que não manifestaram essa dificuldade justificaram da seguinte forma: nunca procuraram as instituições do sistema financeiro, portanto não percebem nenhum problema no acesso. Consideramos essas declarações como evidências da autoexclusão: os bancos não fazem parte do cotidiano de muitas dessas pessoas porque elas consideram que esse tipo de serviço não é compatível com sua condição social e econômica. Dessa forma, um 
meio alternativo, como o Banco Bem, é uma saída plausível para aqueles que precisam de certos serviços financeiros que lhes são inacessíveis no sistema formal.

Procuramos captar também a percepção de melhoria da situação financeira causada pelo uso da moeda e a crença na continuação da sua existência. Todas as pessoas consideraram que a moeda local melhorou sua situação financeira, havendo 13 respostas que salientaram que esse avanço foi grande. Voltamos a enfatizar o fato de que, a despeito de a quantidade de unidades monetárias utilizadas por essas pessoas ser exígua, sua situação financeira é tão débil que a diferença percebida é grande. Todos também afirmaram ter confiança na continuidade da moeda, o que, como vimos teoricamente, é um fator essencial ao sucesso de um SML.

Avançamos, então, para a segunda parte das entrevistas estruturadas, que teve como foco os estabelecimentos e negócios que aceitam a moeda bem como pagamento pelos seus bens e/ou serviços. São 38 os empreendimentos cadastrados e são estimados em 11 os que efetivamente já receberam a moeda local durante a realização de trocas. A nossa amostra consiste em 15 estabelecimentos, portanto abrange todos os que manusearam a moeda, além de 4 que ainda não participaram ativamente desse circuito. Os entrevistados corresponderam a $39 \%$ da populaçãoalvo. São 4 empreendimentos informais (um salão de beleza, uma peixaria, uma mercearia e uma quitanda) e 11 formais (uma sapataria, uma pizzaria, dois taxistas, um supermercado, uma farmácia, uma loja de materiais de construção, um vendedor de gás e água, uma padaria, uma loja de bicicletas e uma mercearia).

A avaliação da moeda bem pelos empreendedores é positiva, assim como o foi no caso dos consumidores. Foi considerada uma ótima ideia por 9 entrevistados e uma boa ideia por 6 deles. Todos afirmaram não criar nenhum tipo de restrição para a aceitação do bem. Novamente, é fortalecida a inferência de que existe otimismo por parte dos usuários da moeda, o que é um pré-requisito para que, com o tempo, ela passe a ser usada por uma quantidade maior de pessoas. Foi possível perceber, ao longo das entrevistas, que as pessoas compreendem que a moeda é um projeto da comunidade ainda em fase inicial e alguns comerciantes ressaltaram a necessidade de ampliar a divulgação.

Durante as entrevistas, ficou claro que os comerciantes acreditam que a moeda é capaz de promover aumento das vendas via incentivo à fidelidade dos clientes. Outro benefício bastante mencionado foi o favorecimento do desenvolvimento local, o que salienta um engajamento de muitos comerciantes no projeto proposto pelo Banco Bem. No entanto, ao contrário dos consumidores, que têm o atraente incentivo de poderem comprar com descontos usando a moeda local, os comerciantes afirmaram que não obtêm nenhum estímulo direto para 
tanto, alegando que o crescimento das vendas ainda não se concretizou. A expectativa de que isso ocorrerá, entretanto, é grande, sobretudo para os pequenos negócios, principalmente quando se observa que outros casos semelhantes, como o Banco Palmas, foram bem-sucedidos nesse propósito. Acreditamos, então, que para o amadurecimento desse processo é muito importante a ampliação da divulgação da moeda, pois foi detectada uma lacuna nesse aspecto, gerada por limitação de tempo e de recursos.

Sobre o vínculo com instituições financeiras formais, 3 empreendimentos não o possuem, sendo dois deles atividades formais e um informal. Há um equilíbrio de uso entre bancos públicos e privados. Dos 12 empreendedores que mantêm relação com o sistema financeiro, 7 possuem conta corrente, 3 possuem, juntamente com conta corrente, aplicações em bancos, e 2 possuem conta poupança. Compreende-se, portanto, que, apesar de ser relativamente menor o número de comerciantes que não usufruem do sistema financeiro, comparando-se à situação dos consumidores, ainda assim o acesso não é sofisticado, limitando-se na maioria das vezes a serviços básicos como manutenção de conta.

A maioria dos entrevistados nunca procurou empréstimo em instituições financeiras: nove entre os 15, muitos deles demonstrando, ao justificar essa ausência de procura, ter uma imagem negativa das instituições financeiras, como um serviço desnecessário e até mesmo prejudicial. Quanto à percepção de melhorias financeiras após a introdução da moeda bem, apenas três dos 15 entrevistados revelaram ter notado uma melhoria significativa, e todos eles têm pequenos empreendimentos informais. Os outros três que afirmaram que a moeda nada melhorou são proprietários ou gerentes dos estabelecimentos cadastrados que ainda não receberam nenhum comprador com a moeda local. Os demais acreditam que a melhoria foi pequena devido à circulação ainda restrita e de exíguo vulto que a moeda possui. Diagnosticamos uma vez mais a necessidade de ampliação do circuito da moeda local, aumentando tanto a quantidade de comerciantes cadastrados quanto de consumidores.

Quanto ao faturamento do negócio, dois interlocutores não quiseram informá-lo, e o restante apenas revelou o rendimento bruto. Pelas informações coletadas, poderiam ser consideradas microempresas 11 das 13 que responderam à pergunta, enquanto as outras duas se enquadrariam na categoria de pequenas empresas. $^{8}$ Associando essa constatação com o panorama de precariedade de acesso aos serviços financeiros, conclui-se que de fato a exclusão financeira está

(8) O Estatuto da Micro e Pequena Empresa (MPE) considera micro aquela empresa com faturamento bruto anual de até $\mathrm{R} \$ 433.755,14$ e pequena a empresa com faturamento bruto anual de até $\mathrm{R} \$$ 2.133.222,00. Para conhecer outras definições de MPE, ver: http://www.sebrae.com.br/br/indicadoresdecompetitividade_mpe/microempresas.asp. 
diretamente relacionada com agentes econômicos de pequeno porte, sejam eles pessoas físicas ou jurídicas.

Afinal, pudemos entender que há um enorme potencial a ser explorado pelo uso de uma moeda própria ao local. Detectamos como principal problema, no caso estudado, o fato de que a sua circulação é ainda restrita, e vimos que existem meios cabíveis de aumentá-la. Nesse processo, insistimos, a publicidade é fundamental. Ao longo da visita aos bairros foi verificado que muitos moradores não conheciam ou não sabiam explicar como a moeda funciona, o mesmo ocorrendo entre os comerciantes, vendedores e produtores locais. Proporcionar campanhas educativas, voltadas para a familiarização com atividades relacionadas às finanças, seria também relevante para diminuir a (auto) exclusão financeira. Outro evento de extrema importância será a efetivação do acordo já celebrado entre o Banco Bem e a CEF que possibilitará aos beneficiados com a Bolsa Família receber uma parte desse valor em bens, caso queiram. Não foi possível obter precisamente o número de pessoas moradoras nos três bairros que desfrutam desse programa, mas a coordenação confirmou que é uma quantidade expressiva, o que portanto fará uma enorme diferença para a ampliação do escopo da moeda local.

Do ponto de vista de uma pesquisa qualitativa, consideramos que o resultado obtido foi satisfatório. A intenção de compreender e descrever um fenômeno monetário local, fruto de um esforço de coesão social e com a finalidade de atenuar condições econômicas e financeiras desfavoráveis, foi almejada.

\section{Considerações finais}

Este artigo trata de um tema ainda bastante incomum no meio acadêmico, desconhecido por alguns e considerado irrelevante para outros. De modo geral, a teoria econômica caminha da teoria para a prática, o que muitas vezes se mostra equivocado devido às limitações que os modelos impõem à realidade. Aqui, a situação é inversa: é a prática que impera, o que foi comprovado com o descobrimento de uma enorme diversidade de experiências existentes em todo o mundo, que proliferam a despeito do desconhecimento por grande parte da academia. Buscamos, então, mesmo que de forma exploratória e embrionária, descobrir de que forma a teoria poderia ser útil para esclarecer esse fenômeno.

Ao estudar a existência de moedas paralelas às convencionais e limitadas no espaço, num mundo cada vez mais global, fica evidenciada uma prática de resistência à imposição de valores e normas externos e alheios à realidade do local. A tentativa de recuperação da capacidade de tomar decisões, como observamos no nosso caso, parte exatamente dos estratos mais prejudicados pelo avanço do capitalismo e seu rompimento de fronteiras. A decisão de usar uma moeda 
alternativa para comprar algo produzido internamente ou vendido na economia local é um ato de proteção.

Indubitavelmente, o principal benefício do uso da moeda local no modelo que os bancos comunitários estipularam no Brasil é a manutenção da riqueza no local, ou melhor, a diminuição dos vazamentos e a consequente valorização da atividade econômica que se realiza na região. Como salienta Delille (2004), a concorrência com as grandes redes de comercialização e produção é muitas vezes desleal e deletéria, e nesse contexto as moedas locais criam um mercado privilegiado onde predominam as preferências coletivas, criadas a partir da informação que essas moedas carregam sobre o potencial de desenvolvimento local e a importância da consciência no momento do consumo. Certamente, essas ideias foram corroboradas durante o estudo de caso, quando percebemos o quanto os usuários da moeda estavam cientes de que isso tinha como finalidade a melhoria da situação econômica e social do lugar onde habitavam.

Entre os problemas encontrados, destacam-se dois, considerados de maior relevância: a fragilidade da coesão social, que ameaça o sucesso das moedas locais, e a má compreensão por parte do Estado, quando se sente ameaçado por essa criação. Para ambos, uma solução é a divulgação. Julgamos ser infundado o temor de que o governo perca o controle da oferta de dinheiro, exatamente, e mais uma vez, pelo caráter local dos SML. O volume de transações é ínfimo em relação às transações monetárias nacionais, e o objetivo da implantação de moedas locais não é a supressão da moeda nacional.

Indispensável realçar, novamente, que não é a simples introdução de uma moeda local capaz de garantir por si só o desenvolvimento local, como lembra Silva (2005). Acreditamos que os Sistemas de Moeda Local não devem ser vistos como uma panaceia, mas exclusivamente como um instrumento inovador que promove o poder local, mesmo com todas as suas limitações. Também não é seguro concluir que as moedas locais têm o poder de eliminar a exclusão financeira. $\mathrm{O}$ que se intencionou foi tão somente apontar para a estreita relação entre essas duas características e mostrar que a criação de uma moeda própria se revela um instrumento criativo de comunidades que buscam amenizar suas privações.

De acordo com Amin et al. (2006), é importante notar que a maioria das experiências de SML tem se mostrado independente tanto do mercado quanto do Estado, o que implica que não é possível generalizar a sua aplicação como um instrumento de política através da simples injeção de recursos no local. Acreditase que os SML não podem ser considerados substitutos de políticas públicas de desenvolvimento econômico ou de provisão de bem-estar social. Devem ser encarados como uma ação adicional e integrada a outras políticas. 
Melissa Silva Menezes

O ensejo de mensurar numericamente os impactos da implantação de uma moeda em um local sujeito à exclusão, não só financeira mas também social e econômica, surgirá depois de passada a fase infante desses projetos. Não obstante, atentamos para a importância de se realizarem estudos de caso comparativos, inclusive em nível internacional, para consolidar uma sistematização. Se a ambição desse trabalho, que foi a de despertar o interesse acadêmico pelo assunto, for alcançada, esperamos que a pesquisa se desenvolva e possibilite uma análise mais abrangente, objetiva e concludente.

\section{Referências bibliográficas}

ALBAGLI, S. Globalização e espacialidade: o novo papel do local. In CASSIOLATO, J. E.; LASTRES, H. M. M. Globalização e inovação localizada: experiências e sistemas locais no Mercosul. Brasília: Ibict, 1999.

AMIM, A.; CAMERON, A.; HUDSON, R. Constructing the social economy through local community initiatives? Economic \& social research council. University of Durham. Disponível em: <www.dur.ac.uk/ dgg0www6/index.htm>. Acesso em: mar. 2006.

BLANC, J. Les monnaies parallèles, une composante normale des usages monétaires. Transversales Science Culture, Paris, n. 58, 1999.

BÚRIGO, F. L. Moeda social e a circulação das riquezas na economia solidária. Goiânia: Rede CTA-UJGoiás, 2001.

CAHN, E. On LETS and time dollars. International Journal of Community Currency Research, v. 5, 2001. Disponível em: <www.geog.le.ac.uk/ijccr/>.

CARVALHO, C. E.; ABRAMOVAY, R. O difícil e custoso acesso ao sistema financeiro. In: SANTOS, C. A. (Org.). Sistema financeiro e as micro e pequenas empresas. Brasília: Sebrae, 2004.

CARVALHO, F. C. de. A teoria monetária de Marx: uma interpretação pós-keynesiana. Revista de Economia Política, v. 6, n. 4, p. 5-21, out./dez. 1986.

A economia keynesiana e a moeda na economia moderna. In: CROCCO, M.; JAYME JR., F. G. (Org.). Moeda e território: uma interpretação da dinâmica regional brasileira. Belo Horizonte: Autêntica, 2006. p. 29-38.

CATO, M. S. Argentina in the Red: what can the UK's regional economies learn from the Argentinean banking crisis? International Journal of Community Currency Research, v. 10, p. 43-55, 2006. Disponível em: <www.geog.le.ac.uk/ijccr/>. Acesso em: set. 2006.

CONTI, S.; GIACCARIA, P. Local development and competitiveness. Chapt. 10: A story still to be told. Kluwer: Dordrecht, 2001.

DOW, S. C. Stages of banking development and the spatial development of financial systems. In: MARTIN, R. (Ed.). Money and the space economy. New York: John Wiley \& Sons, 1999. p. 31-48.

HARVEY, D. The urbanization of capital. Oxford: Johns Hopkins University, 1985. $259 \mathrm{p}$. 
JACOBS, J. Cities and the wealth of nations: principals of economic life. New York: Random House, 1984.

KEYNES, J. M. Teoria geral do emprego, do juro e do dinheiro. Rio de Janeiro: Editora Fundo de Cultura, 1964.

KUMAR, A. (Coord.). Brasil: acesso a serviços financeiros. Rio de Janeiro: Ipea, Banco Mundial, 2004. 628p.

LAACHER, S. Nouvelles formes de sociabilité ou les limites d'une utopie politique: l'exemple des systèmes d'échange local. International Journal of Community Currency Research, v. 3, 1999. Disponível em: <www.geog.le.ac.uk/ijccr/>.

LEE, R. Moral money? LETS and the social construction of local economic geographies in Southeast England. Environment and Planning A, v. 28, p. 1377-1394, 1996.

Local money: geographies of autonomy and resistance? In: MARTIN, R. Money and space economy. New York: Wiley \& Sons, 1999. p. 207-224.

LEYSHON, A. Money and finance. In: SHEPPARD, E.; BARNES, T. A companion to economic geography. Cornwall, UK: Blackwell, 2003. Cap. 26, p. 432-449.

; LEE, R. Introduction: alternative economic geographies. In: LEYSHON, A.; LEE, R.; WILLIAMS, C. C. (Ed.). Alternative economic spaces. London: Sage, 2003. p. $1-26$.

; THRIFT, N. Financial exclusion and the shifting boundaries of the financial system. Environment and Planning A, v. 28, p. 1150-1156, 1996.

1997.

Money/Space: geographies of monetary transformation. London: Routledge,

LIEATER, B. The future of money: creating new wealth, work and a wiser world. London: Century, 2001.

LINTON, M.; SOUTAR, A. The LETSystem design manual. Courtenay, CA: Landsman Community, 1994. Disponível em: <http://www.gmlets.u-net.com/design/home.html>. Acesso em: fev. 2006.

MARTIN, R. Money and space economy. New York: Wiley \& Sons, 1999.

MUNDELL, R.A. International economics. New York: Macmillan, 1968. p. 177-186.

PACIONE, M. Local exchange trading systems as a response to the globalization of capitalism. Urban Studies, v. 34, n. 8, p. 1179-1199, 1997.

VITÓRIA, ES. Prefeitura Municipal (2004). Índice de Qualidade Urbana (IQU): bairros de Vitória - 1991 e 2000. Vitória: Coordenadoria de Planejamento, 2004. Disponível em: $<$ http://www.vitoria.es.gov.br/secretarias/estrategica/iqu1991a2000.htm>. Acesso em: set. 2006.

PRIMAVERA, H. Riqueza, dinero y poder: el efímero "milagro argentino" de las redes de trueque. In: HINTZE, S. (Org). Trueque y economia solidária. ICO, Universidad Nacional de General Sarmiento, 2003. Disponível em: <www.biblioteca.clacso.edu.ar/>. Acesso em: ago. 2006. 
Melissa Silva Menezes

PURDUE, D.; DURRSCHMIDT, J.; JOWERS, P.; O'DOHERTY, R. DIY Culture and extended Milieux: LETS, Veggie Boxes and Festivals. The Sociological Review, p. 645667, 1997.

RBC - REDE DE BANCOS COMUNITÁRIOS. Banco Comunitário: serviços financeiros solidários em rede. Fortaleza: Instituto Palmas, jan. 2006.

SCHRAVEN, J. The economics of local exchange and trading systems: a theoretical perspective. International Journal of Community Currency Research, v. 4, 2000. Disponível em: <www.geog.le.ac.uk/ijccr/>.

Mutual credit systems and the commons problem: why community currency systems such as LETS need not collapse under opportunistic behaviour. International Journal of Community Currency Research, v. 5, 2001a. Disponível em: $<$ www.geog.le.ac.uk/ijccr/>.

. The economics of community currencies: a theoretical perspective. Unpublished Honours Thesis-Oxford University, 2001b. Disponível em: <www.jorim.nl/economicscommunitycurrencies.html>. Acesso em: maio 2006.

SICSÚ, J.; CROCCO, M. Em busca de uma teoria de localização das agências bancárias: algumas evidências do caso brasileiro. Revista Economia, Niterói, v. 4, n. 1, p. 85-112, 2003.

SILVA, Janaína Carneiro. Rubem Berta's complementary currency: an evaluation of the initial stage of the experience of a Southern Brazilian local community on Implementing its own complementary currency. Master of Arts of Development Management-University of Westminster, London, 2005. Disponível em: <www.strohalm.net/en/reportRB.html>. Acesso em: nov. 2006.

SWYNGEDOUW, E. A. The heart of the place: the resurrection of locality in an age of hyperspace. Geografiska Annsier, v. 71, n. 8, 1989.

WILLIAMS, C. C.; ALDRIDGE, T.; TOOKE, J.; LEE, R.; LEYSHON, A.; THRIFT, N. The role of the third sector in paving a 'Third Way': some lessons from local exchange and trading schemes in the UK. International Journal of Community Currency Research, v. 5, 2001. Disponível em: <www.geog.le.ac.uk/ijccr/>. 